EESTI NSV TEADUSTE AKADEEMIA TOIMETISED. VII KOIDE

BIOLOOGILINE SEERIA. 1958, NR. 1

ИЗВЕСТИЯ АКАДЕМИИ НАУК ЭСТОНСКОИ ССР. ТОМ VII

СЕРИЯ БНОЛОГИЧЕСКАЯ. 1958, № 1

\title{
СТОК ВЕСЕННЕГО ПОСЕВНОГО ПЕРИОДА
}

\author{
К. т. Хоммик, \\ кандидат технических наук
}

При проектировании осушительных систем для участков, предназначенных под полевые культуры, необходимо ориентироваться на сток весеннего посевного периода. Осушительные системы должны создать на осушаемой территории условия, обеспечивающие возможность свободного передвижения сельскохозяйственных машин в период весеннего сева, а также благоприятные условия для развития растений в период вегетации.

В литературе имеется ряд формул для вычисления величины предпосевного и посевного стока (формулы ВНИИГиМ и СНИИГиМ [ $\left.{ }^{1}\right]$, А. И. Ивицкого $\left[{ }^{2}\right]$, А. В. Огиевского $\left[{ }^{3}\right]$, С. И. Харченко $\left[{ }^{4}\right]$, Д. Л. Соколовского $\left[{ }^{5}\right]$ и другие). По этим формулам посевной сток вычисляется с учетом влияния различных факторов, таких как площадь водосбора, рельеф, заболоченность, лесистость, а также степень канализации водосбора (в формулах СНИИГиМ Г. А. Алексеева). Следует, однако, отметить, что до настоящего времени нет еще достаточной ясности в вопросе о характере влияния всех этих факторов. Например, площадь водосбора и уклон поверхности в одних формулах находятся в знаменателе, в других - в числителе. В связи с этим можно считать, что вопрос о посевном стоке требует дополнительной разработки.

Изучение режима стока в весенний посевной период в условиях Әстонской ССР проводилось на основе анализа элементов гидрографов весенних паводков.

Весной 1951 г. в водосборах рек ЭССР наблюдались весьма значительные максимумы, повторяемость которых составляла около $10 \%$. С целью изучения характера стока весеннего паводка в период спада, т. е. в предпосевной и посевной периоды, были обработаны гидрометрические данные наблюдений за 1951 г. по 47 пунктам сети Управления гидрометслужбы ЭССР, а также по трем самым малым по площади (от 1,7 до 36 га) водосборам, наблюдения на которых проводились Академией наук ЭССР

Для всех гидрометрических створов были определены объемы весеннего паводкового стока 1951 г. посредством последовательного суммирования среднесуточных расходов, начиная с 1 апреля и кончая датой, когда размеры суточных расходов (после паводка) соответствовали расходам на 1 апреля (до начала паводка). Если сток с водосборов происходит за счет притока грунтовых вод, то запасы стекающих вод, при равной величине стока в одном и том же водосборе, должны быть тоже равны. К 1 апрелю еще не наблюдалось стока талых вод, следовательно, не могло быть и поверхностного стока. В конце спада весеннего половодья в мае 1951 г. количество осадков было значительно меньше суммы испарения, и сток с водосборов в это время происходил главным образом за счет запасов воды. Таким образом, оказалось возможным суммировать расхо- 
ды на подъеме и спаде грунтовых вод при равной величине запасов воды в водосборе и охватить весь объем стока за весенний период.

Сравнение суммарного слоя весеннего паводкового стока 1951 г. по различным водосборам показывает, что этот слой изменяется в довольно больших пределах от 96 до 196 мм. В это время сумма осадков, образующих весенний паводок, колебалась от 137 до 171 мм. Таким образом было установлено, что в некоторых случаях объем стока превышал объемы воды, накопленные в снеговых запасах водосбора, сложенные с разностью между суммой дождевых осадков и испарением за рассматриваемый период. Отрицательная разность между осадками и стоком является физически необъяснимой и может быть обусловлена различными ошибками и неточностями при определении величины осадков, стока, площади водосбора, испарения и различных запасов воды, принимающих участие в кругообороте влаги.

Среднее арифметическое значение слоя весенних запасов воды, образующих сток с водосборов, получается (с учетом испарения) на 14 мм больше среднего слоя паводкового стока. Из этого можно заключить, что размер испарения во время паводка в апреле принят в среднем на 14 мм меньше действительного. Других систематических ошибок в расчете не наблюдается, и остальные ошибки носят, по-видимаму, случайный характер. Случайные ошибки в размерах элементов водного баланса, таких как осадки, сток, испарение и запасы воды в водосборах, находятся обычно в пределах точности определения, и обнаружить их трудно.

В величине площади водосборов, однако, могут встречаться ошибки, которые заметно влияют на размеры определяемых модулей или слоя стока. Известно, что не всегда поверхностная водораздельная линия совпадает с подземным водоразделом грунтовых вод. Чтобы избежать возможных ошибок в площадях водосборов, целесообразно принять за единицу измерения стока размер среднегодового стока. В этом случае, как известно, водосборная площадь вообще в расчет не входит. При выражении стока в этих единицах учитывается в некоторой мере и типичный характер распределения осадков данного района и значительно сглаживаются расхождения в слое стока весеннего паводка по различным водосборам.

Ввиду того, что в суммарном слое стока весеннего паводка 1951 г. в водосборах ӘССР не было больших расхождений, величина таких характеристик паводка, как его продолжительность и максимальный сток, зависит лишь от различных физико-географических факторов.

Продолжительность спада паводка определена по гидрографам весеннего половодья. Гидрографы рек ЭССР имеют обычно крутую линию спада. По мере убывания стока линии спада принимают форму выгнутой кривой с крутизной, зависящей от зарегулированности поверхностного стока. Концевая часть кривой спада обычно представляет собой пологую линию с незначительным уклоном. Нормальный вид кривой спада может нарушаться вторичными подъемами, обусловленными выпадением дождей в период спада. Чтобы устранить влияние дождей на форму кривой спада, при исследовании выбирались промежутки без осадков, и путем соединения их в одну плавную линию получались так называемые нормальные кривые спада для каждого гидрометрического створа. На нормальной кривой спада определяется точка, где кривая переходит в почти прямую линию с очень малым размером спада (около 3 л/сек км² и менее в течение 30 суток). Начиная с этой точки, сток образуется главным образом за счет запасов грунтовых вод. Точку перегиба на нормальной кривой спада можно считать концом паводка. На гидрографах 1951 г. конец весеннего паводка несколько растянут. 
Вызвано это тем, что в описываемом году во время спада весеннего паводка выпадали дожди, которые отодвинули конец паводка в среднем на 9 суток. Чтобы исключить влияние осадков на продолжительность спада паводка, срок был подсчитан в конце паводка по нормальным кривым спада.

Средняя фактическая продолжительность спада весеннего паводка 1951 г. в водосборах, по которым имелись данные наблюдений, составляла 41 сутки, а по нормальным кривым спада - 32 суток. Наименьшая продолжительность спада, 7 суток, наблюдалась на осушенных участках тяжелых суглинистых почв. В водосборах с большими озерами или с обильным стоком подземных вод продолжительность спада паводка 1951 г. составляла, по нормальным кривым, 45-48 суток.

Средняя продолжительность подъема паводка оказалась равной 10 суткам, колеблясь в пределах от 2 суток (на осушенных участках, расположенных на тяжелых почвах) до 17 суток (в водосборах с большими озерами).

Факторы, влияющие в сторону уменышения максимального стока (озерность, хорошая проницаемость почво-грунтов, заболоченность, лесистость водосборов и т. п.), увеличивают продолжительность спада паводка, и, наоборот, в водосборах, где отсутствуют регулирующие факторы, максимумы стока увеличиваются, а продолжительность спада волны паводка уменьшается.

Таким образом, при одном и том же объеме паводка для различных водосборов должна существовать обратная связь между максимумом и продолжительностью спада паводка. Действительно, корреляция логарифмов чисел продолжительности спада паводка 1951 г. с логарифмами чисел максимального стока, измеряемого в принятых единицах, дает следующую связь:

$$
\lg t_{\mathrm{c} 1951}=-0,333 \lg k_{\text {вес, макс } 1951}+1,91
$$

с коэффициентом корреляции $r=-0,90$. Здесь $t_{\text {с } 1951}-$ продолжитель-

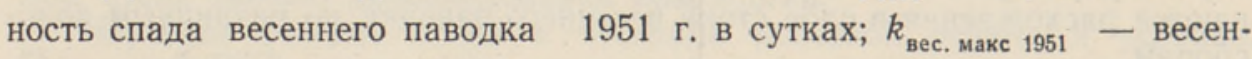
ний максимальный сток 1951 г. в единицах от многолетнего среднегодового стока.

Так как обеспеченность максимального стока 1951 г. составляла около $10 \%$, то уравнение действительно при обеспеченности максимального стока в $10 \%$.

По нормальным кривым спада определена продолжительность спада для обеспеченности максимального стока в 20 и $30 \%$. На основании корреляции получены следующие уравнения продолжительности спада:

для максимального стока с обеспеченностью в $20 \%$

$$
\lg t_{\mathrm{c} 20 \%}=-0,333 \lg k_{\text {вес. макс } 20 \%}+1,86
$$

и для максимального стока с обеспеченностью в $30 \%$

$$
\lg t_{\mathrm{c} 30 \%}=-0,333 \lg k_{\text {вес. макс } 30 \%}+1,81 \text {. }
$$

Все три уравнения (1), (2) и (3) отличаются только по величине свободного члена. В диапазоне обеспеченности максимального стока от 10 до $30 \%$ можно для свободного члена в уравнении продолжительности спада написать следующее выражение; 


$$
a=-0,21 \lg P+2,12,
$$

где $a-$ свободный член в уравнениях (1), (2) и (3);

$P$ - процент обеспеченности весеннего максимального стока.

Таким образом, уравнение продолжительности спада весеннего паводка при максимальном стоке с обеспеченностью от 10 до $30 \%$ можно записать в общем виде:

$$
\begin{aligned}
& \lg t_{\mathrm{c} 10-30 \%}=-0,333 \lg k_{\text {iec, мaหс } 10-36 \%}-0,21 \lg P+2,12 \\
& \text { или } t_{\mathrm{c} 10-30 \%}=\frac{132}{\sqrt[3]{k_{\text {вес. макс } 10-30 \%}} P^{0,21}} \text {. }
\end{aligned}
$$

При установлении вида уравнения кривых спада принимаем, что во время посевного периода они представляют собой параболы. Если построить кривую спада в логарифмических координатах, то тангенс угла, образуемый касательной к этой кривой и осью абсцисс, является показателем степени кривой спада. Ввиду того, что логарифмическая анаморфоза представляет собой кривую, тангенс и, следовательно, показатель степени кривой спада представляет собой величину переменную. Однако для отдельных участков кривой спада, например посевного периода, эту степень можно принять постоянной.

Если выражать ординаты кривой спада в долях от максимального стока $\left(k_{\text {вес, макс }}\right)$, а абсциссы в долях от продолжительности периода спада $\left(t_{c}\right)$, то:

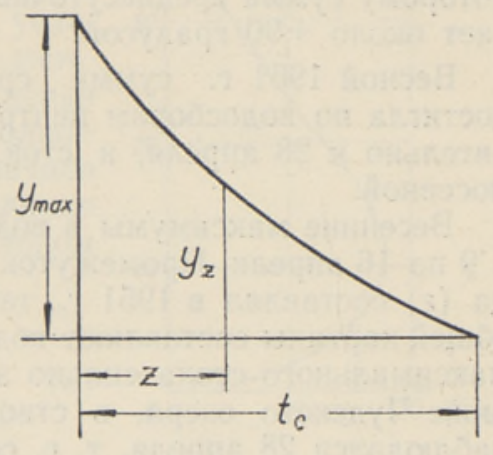

$$
y_{\mathrm{z}}=\frac{k_{\mathrm{z}}}{k_{\text {вес. макс }}} \text { и } x_{\mathrm{z}}=\frac{t_{\mathrm{c}}-z}{t_{\mathrm{c}}} .
$$

Принимая, по Д: Л. Соколовскому, для кривой спада параболу вида $y_{\mathrm{z}}=x_{\mathrm{z}}^{\mathrm{n}}$, получим

$$
\lg y_{\mathrm{z}}=n \lg x_{\mathrm{z}} \text { и } n=\frac{\lg y_{\mathrm{z}}}{\lg x_{\mathrm{z}}}=\lg \frac{k_{\mathrm{z}}}{k_{\text {вес. макс }}}: \lg \frac{t_{\mathrm{c}}-z}{t_{\mathrm{c}}} .
$$

Нас интересует показатель степени кривой спада в посевной период. Поэтому при вычислении показателя $n$ следует в уравнение (5) вместо $k_{z}$ подставить сток посевного периода $k_{\text {пос }}$, а вместо $z-$ число суток от максимума до ординаты посевного периода.

При использовании данных наблюдений для вычисления показателя $n$ необходимо вычесть из общей величины посевного стока сток грунтовых вод в данном водосборе. В противном случае не будет выполнено условие, чтобы при $\quad x_{\mathrm{z}}=0 \quad y_{\mathrm{z}}=0$, как это следует из уравнения $y_{\mathrm{z}}=x_{\mathrm{z}}^{\mathrm{n}}$. Таким образом, показатель степени кривой спада стока посевного периода можно вычислить по следующему уравнению:

$$
n=\lg \frac{k_{\text {пос }}-k_{\text {гр }}}{k_{\text {вес. макс }}}: \lg \frac{t_{\mathrm{c}}-z}{t_{\mathrm{c}}}
$$




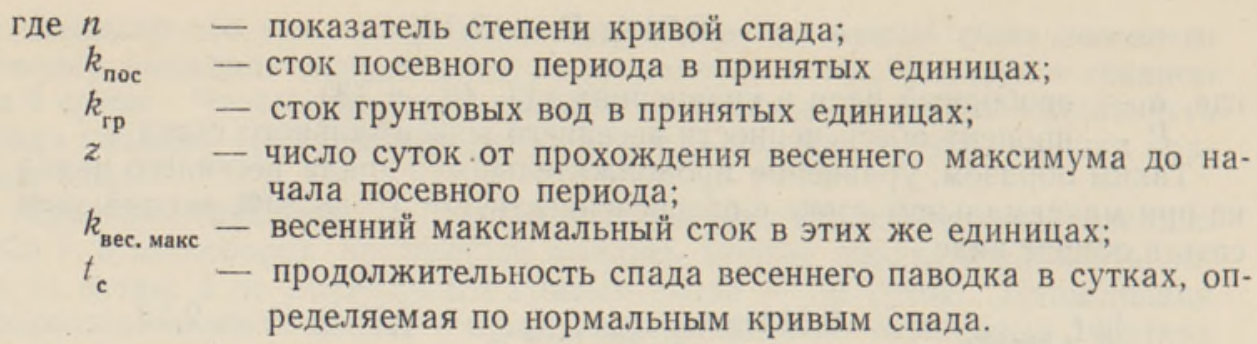

При использовании данных гидрометрических измерений в период паводка 1951 г. для вычисления показателя степени кривой спада была определена дата начала посевного периода. На основании многолетних исследований Э. К. Халлера $\left[{ }^{6}\right]$ по вопросу выбора посевного периода для яровых зерновых культур и с учетом исследований А. И. Ивицкого $\left[{ }^{2}\right]$ установлено, что оптимальным сроком посева яровых зерновых культур в климатических условиях ӘССР можно приближенно считать срок, к которому сумма среднесуточных температур с начала снеготаяния достигает около +90 градусов.

Весной 1951 г. сумма среднесуточных положительных температур достигла по водосборам центральной Эстонии 90-100 градусов приблизительно к 28 апреля, и сток, соответствующий этой дате, принят за посевной.

Весенние максимумы в водосборах рек ЭССР наблюдались в 1951 г. с 9 по 16 апреля. Промежуток от максимума до начала посевного периода $(z)$ составлял в 1951 г., таким образом, 12-19 суток. Исключение из общей картины составляют водосборы с большими озерами, где появление максимального стока сильно запаздывает. Так, например, в реке Нарве, ниже Чудского озера, в створе Васькнарва, максимум стока 1951 г. наблюдался 28 апреля, т. е. совпадал с началом посевного периода. В водосборах южной Әстонии продолжительность периода между максимумом и сроком посева оказалась в среднем на 1-2 суток больше, чем в северной Әстонии. Видимо, в южных районах наступление срока сева происходит также в среднем на $1-2$ дня раньше, чем в северных. В наших расчетах был принят один и тот же срок посева (28 IV) для всей территории республики, что вносит некоторую неточность, однако отклонение на $1-2$ дня в сроке сева, хотя оно и влияет в некоторой мере на величину посевного стока, не имеет значения при вычислении показателя степени кривой спада.

При исследовании показателя степени кривой спада, как было сказано выше, необходимо исключить сток грунтовых вод из нижней части кривой спада паводка. Величину стока грунтовых вод можно определить по нормальным кривым спада. Сток, соответствующий точке перегиба на кривой спада, где кончается паводок и начинается более медленный спад за счет убывания запаса грунтовых вод, и является интересующим нас стоком грунтовых вод.

Результаты вычисления показателя степени кривой спада весеннего паводка показывают, что в большинстве водосборов величина его колеблется в узких пределах. Средний показатель для водосборов, по которым имеются данные наблюдений, равен 3,72 со средним квадратичным отклонением 0,49 . Небольшое отклонение среднего арифметического показывает, что для всех водосборов можно применять постоянную величину показателя степени кривой спада посевного периода, которую можно принять равной 3,7 .

Зная продолжительность спада весеннего паводка $t_{\mathrm{c}}$, определяемого 
по формуле (4), и имея данные о характере кривых спада в виде показателя степени $n=3,7$, можно на основании формулы (6) написать следующую формулу посевного стока:

$$
k_{\text {пос }}=k_{\text {вес. макс }}\left(1-\frac{z P^{0,21}}{132} \sqrt[3]{k_{\text {вес. макс }}}\right)^{3,7}+k_{\text {гр }} .
$$

Число суток $z$ от момента прохождения весеннего максимума до начала посевного периода зависит, кроме климатических факторов, от целого ряда особенностей водосборов. Можно предполагать, что такие факторы, как площадь водосбора, залесенность, заболоченность, озерность, водопроницаемость почво-грунтов и т. п., приводят к запаздыванию наступления максимума и к уменьшению продолжительности $z$. Эти факторы уменьшают также и размеры самих максимумов. Следовательно, при одинаковых климатических условиях с уменьшением максимального стока можно ожидать запоздания срока его прохождения и, как следствие этого, уменьшения продолжительности промежутка максимума до начала посевного периода. На основании корреляции продолжительности $z$ с максимальным стоком 1951 г. получено следующее уравнение:

$$
z=0,16 k_{\text {вес. макс }}+12,5 \text {. }
$$

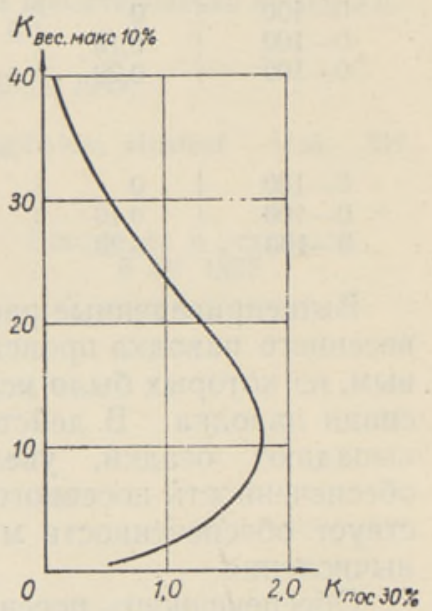

Графическое изображение формулы (7) для Рис. 2 обеспеченности максимальнога стока $10 \%$ и и $k_{\text {гр }}=0$ приведено на рис. 2. При этом продолжительность $t_{\text {c }}$ и $z$ вычислялась по формулам (4) и (8). Из рис. 2 видно, что при $k_{\text {вес.макс }}<10$ с увеличением максимального стока увеличивается и посевной сток. При $k_{\text {вес. макс }}>10$ с увеличением максимального стока посевной сток начинает

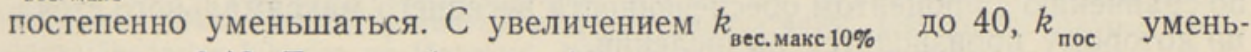
шается до 0,12 . Таким образом, факторы, влияющие в сторону уменьшения максимального стока (заболоченность, лесистость, водопроницаемость почво-грунтов и т. п.), обычно увеличивают посевной сток.

После канализации и осушения водосбора ожидается увеличение максимального стока, а в обычных условиях и уменьшение посевного стока.

В табл. 1 приведены результаты определения величины стока посевного периода по формуле (7) до и после осушения для водосборов, характеризуемых следующими данными: площадь водосбора $F=0-100$ км$^{2}$; коэффициент среднего минимального стока $k_{95 \%}=0,0,10$ и 0,20 ; процент заболоченности водосбора $A=100 \%$; процент лесистости $B=0$; процент обеспеченности весеннего максимального стока $P=10 \%$; коэффициент влияния канализации водосбора $\varepsilon=0,80$ (до осушения) и 1,23 (после осушения); коэффициент грунтового стока $k_{\text {гр }}$ принят равным $2,5 k_{95 \%}$.

Как видно из таблицы, при осушении малых $\left(F \leqslant 100 \mathrm{Kм}^{2}\right)$ заболоченных водосборов без грунтового питания $\left(k_{95 \%}=0\right)$ ожидается уменьшение стока посевного периода порядка $34 \%$. Осушение заболоченных тер- 
риторий с обильным стоком грунтовых вод $\left(k_{95 \%}>0,10\right)$ к значительному изменению стока посевного периода привести не должно.

Таблица 1

Сток посевного периода до и после осушения

\begin{tabular}{|c|c|c|c|c|c|c|}
\hline \multirow{2}{*}{$\begin{array}{c}\text { Площадь } \\
\text { водосбора } F \\
\text { в км² }\end{array}$} & \multicolumn{5}{|c|}{$\begin{array}{c}\text { Сток в единицах от многолетнего } \\
\text { среднегодового стока }\end{array}$} & \multirow{2}{*}{$\begin{array}{c}\text { У }_{\text {меньшение }} \\
k_{\text {пос }} \text { после } \\
\text { осушения в } \\
\%\end{array}$} \\
\hline & $k_{95 \%}$ & $k_{\text {вес.макс } 10 \%}$ & $k_{\text {noc }}$. & $\begin{aligned} & k_{\mathrm{rp}}= \\
= & 2,5 k_{95 \%}\end{aligned}$ & $k_{\text {пос }}+k_{\text {гр }}$ & \\
\hline
\end{tabular}

\begin{tabular}{|c|c|c|c|c|c|}
\hline $\begin{array}{l}0-100 \\
0-100 \\
0-100\end{array}$ & $\begin{array}{l}0 \\
0,10 \\
0,20\end{array}$ & $\begin{array}{r}14,5 \\
10,6 \\
7,6\end{array}$ & $\begin{array}{l}1,67 \\
1,77 \\
1,70\end{array}$ & $\begin{array}{l}0 \\
0,25 \\
0,50\end{array}$ & $\begin{array}{l}1,67 \\
2,02 \\
2,20\end{array}$ \\
\hline \multicolumn{6}{|c|}{ После осушения } \\
\hline $\begin{array}{l}0-100 \\
0-100 \\
0-100\end{array}$ & $\begin{array}{l}0 \\
0,10 \\
0,20\end{array}$ & $\begin{array}{l}22,4 \\
16,2 \\
11,8\end{array}$ & $\begin{array}{l}1,10 \\
1,57 \\
1,77\end{array}$ & $\begin{array}{l}0 \\
0,25 \\
0,50\end{array}$ & $\begin{array}{l}1,10 \\
1,82 \\
2,27\end{array}$ \\
\hline
\end{tabular}

Вышеприведенные расчеты основывались на предположении, что спад весеннего паводка происходит по нормальным кривым спада, т. е. по кривым, из которых было исключено влияние осадков, выпадающих в период спада паводка. В действительности же в период спада почти ежегодно выпадают осадки, увеличивающие сток посевного периода. Поэтому обеспеченность посевного стока, вычисленная по формуле (7), не соответствует обеспеченности максимального стока, по которому производятся вычисления.

Обеспеченность посевного стока в зависимости от обеспеченности максимального стока можно найти по способу сравнения вычисленных данных с фактически наблюденными. По створам, где имеются многолетние гидрометрические наблюдения, были составлены эмпирические кривые обеспеченности посевного стока. Сравнение эмпирических кривых с вычисленными показывает, что обеспеченность вычисленного стока в среднем на $20 \%$ ниже фактического. В связи с этим обеспеченность вычисленного стока посевного стока посевного периода следует увеличить на $20 \%$ по сравнению с процентом обеспеченности весеннего максимального стока, по которому производятся вычисления.

Таким образом, формулу (7) стока посевного периода следует использовать в следующем виде:

$$
k_{\text {пос } P+20 \%}=k_{\text {вес. макс } P \%}\left(1-\frac{z P^{0,21}}{132} \sqrt[3]{k_{\text {вес. макс } P \%}}\right)^{3,7}+k_{\text {гр }},
$$

где $k_{\text {пос } P}+20 \%$ - сток посевного периода в единицах от многолетнего среднегодового стока при обеспеченности $P+20 \%$;

$k_{\text {вес. макс } \mathrm{p} \%}$ - весенний максимальный сток в единицах от многолетнего стока при обеспеченности $Р \%$;

$$
z=0,16 k_{\text {вес. макс } P \%}+12,5 ;
$$

$\boldsymbol{k}_{\text {гр }}$-сток грунтовых вод в единицах от многолетнего среднегодового стока; при отсутствии данных наблюдений можно $k_{\mathrm{rp}}$ определить по карте среднего минимального стока $\left[{ }^{7}\right]$, увеличивая полученную по карте величину в 2,5 раза. 


\title{
ЛИТЕРАТУРА
}

1. Костяков А. Н., Основы мелиорацин. М., 1951.

2. И вицкий А. И., Предпосевной период и предпосевно-посевной сток в условиях БССР. Труды Института болотного хозяйства БССР, т. 1, Минск, 1939.

3. Ог и ев к и й А. В., Новые нормы гидрологических расчетов для проектировок по осушению в условиях УССР. Сборник научных работ Киевского гидромелиоративного института, вып. 2, 1949.

4. Х а р ч е нко С. И., О гидрологических расчетах при проектировании осушительных систем в Барабинской низменности. Труды ГГИ, вып. 38 (92), Гидрометеоиз. дат, 1953.

5. С околов ски й Д. Л., О методике расчета стока при проектированни осушительных систем. Гидротехника и мелиорация, 1953, № 6.

6. H a lle r, E., Suviteraviljade külviaegade valikust. Tallinn, 1947.

7. $\mathrm{H}$ o m mik, K., Kuivendussüsteemide arvutuse hüdroloogilistest alustest. Изв. АН ЭССР, Серия биологическая, 1956, № 2. Эстонский научно-исследовательский институт
земледелия и мелиорации
Поступила в редакцию

9 IV 1957

\section{KULVIAEGNE ÄRAVOOL}

\author{
K. Hommik, \\ tehniliste teaduste kandidaat
}

Resümee

Kevadise külviaegse äravoolu suuruse uurimisel vōeti aluseks kevadise suurvee vaatlusandmed. 1951. aasta kevadel esinesid Eesti NSV vesikondades suurvee maksimumid, mille tõenäosus oli ligikaudu $10 \%$. Neil andmetel koostati kevadise äravoolu langjooned jōgede kohta, kus tehti hüdromeetrilisi vaatlusi. Langjoonte koostamisel valiti suurvee ălanemise hüdrograafi osad, kus puudusid sademete môjul esinenud muudatused äravoolu alanemises. Kuiva aja langjoonte ühendamisega üheks pidevaks kõverjooneks saadi nn. normaal-langjooned, s. o. kevadised hüdrograafid sel juhul, kui suurvee alanemise ajal puuduksid sademed. Normaal-langjoonel eraldati punkt, kus kõverjoon muutub peaaegu sirgeks, omades õige vähest langu (ligikaudu $3 \mathrm{l} / \mathrm{sek} . \mathrm{km}^{2} 30$ päeva kestel). Sellest punktist alates toimub äravool peamiselt pōhjavete tagavaradest, sest kiirem äravool maapinna lähedastes kihtides on lōppenud. Nimetatud käänupunkt normaal-langjoonel vōeti suurvee alanemise lōpuks.

Kevadise suurvee alanemise kestus $\left(t_{\mathrm{c}}\right)$, s. o. ajavahemik maksimaalsest äravoolust kuni kevadise suurvee lōpuni, on arvutatav kevadise maksimaalse äravoolu ( $\left.k_{\text {kev. } \max P \%}\right)$ andmetel valem (4) alusel.

Metsade ja soodega kaetud vesikondades esinevad kevadise suurvee maksimumid hiljem kui samades klimaatilistes tingimustes lagedates vesikondades. Samuti on metsade ja soodega kaetud vesikondades maksimumid vähemad kui lagedates vesikondades. Seega on ühesugustes klimaatilistes tingimustes ajavahemik kevadise suurvee maksimumist kuni külviajani suhteliselt väiksemate maksimumide puhul väiksem kui suuremate maksimumidega lagedates vesikondades. Valem (8) alusel vōib määrata ajavahemiku kestuse (z) maksimaalsest äravoolust kuni külviajani.

Normaal-langjoonte ordinaatide arvutamiseks külviajal on koostatud valem (7). Kuna tegelikud suurvee langjooned erinevad normaal-langjoontest, siis on tōelise hüdrograafi ordinaatide (s. o. äravoolu) arvutamiseks külviajal vajalik valemisse (7) viia vastav parandus. Valem (7) alusel arvutatud külviaegse äravoolu suuruste võrdlus pikaajalisest. (31 a.) vaatlusreast saadud tegelikkude suurustega näitab, et andmed on vōrreldavad, kui arvutatud külviaegse äravoolu tōenäosus vōtta $20 \%$ võ̃ra suurem kevadise maksimaalse äravoolu tõenäosusest, mille alusel toimub arvutus. Seega on külviaegse äravoolu valemil järgmine kuju: 


$$
k_{\text {kulv } P+20 \%}=k_{\text {kev.max } P \% \%}\left(1-\frac{z P^{0,21}}{132} \sqrt[3]{k_{\text {kev.max } P \%}}\right)^{3,7}+k_{\mathrm{p}} \text {, }
$$

kus $k_{\text {kulv } P+20 \%}$ - kevadine külviaegne äravool tõenäosusega $P+20 \%$ pikaajalise aastakeskmise äravoolu üksustes;

$k_{\text {kev.max } P \%}-$ kevadine maksimaalne äravool tōenäosusega $P \%$ pikaajalise aastakeskmise äravoolu üksustes;

$z$ - ajavahemiku kestus kevadisest maksimaalsest äravoolust kuni külviajani päevades; arvutatakse valem (8) alusel;

$k_{\mathrm{p}}$ - pōhjavee äravool kevadise suurvee lōpul pikaajalise aastakeskmise äravoolu üksustes. Vaatlusandmete puudumisel võib kasutada $k_{\mathrm{p}}$ arvutamiseks keskmist miinimumäravoolu $k_{95 \%}$, korrutades seda koefitsiendiga $2,5 \quad\left(k_{\mathrm{p}}=2,5 k_{95 \%}\right)$.
Eesti Maaviljeluse ja Maaparanduse
Saabus toimetusse
Teadusliku Uurimise Instituut
9. IV 1957

\section{ABFLUSSBEDINGUNGEN WÄHREND DER FRUHJAHRSAUSSAAT}

\section{K. Hommik}

\section{Zusammenfassung}

Die Untersuchungen der Abflussbedingungen während der Frühjahrsaussaat sind auf den Abflussangaben des Frühjahrs-Hochwassers basiert. Im Frühjahr 1951 gab es ein Hochwasser, dessen Wahrscheinlichkeit ungefähr $10 \mathrm{v}$. H. war. Auf Grund der Angaben des Hochwasserabflusses des Frühjahrs 1951 wurden Hochwasser-Senkungslinien zusammengestellt. Bei der Zusammenstellung der Senkungslinien wurden die Abschnitte der Abflussganglinie, die durch Regenfälle beeinflusst waren, weggelassen. Nach der sog. Normalen-Abfluss-Senkungslinie der Trockenzeit wurde die Formel (7) für den Abfluss während der Frühjahrsaussaat gefunden.

In natürlichen Verhältnissen ist der Abfluss der Saatzeit grösser als nach Formel (7) berechnet, da die Abfluss-Senkungslinien immer durch Regenfälle beeinflusst werden. Der Vergleich des nach Formel (7) berechneten Abflusses mit der beobachteten Grösse zeigt, dass die beiden Angaben nur dann vergleichbar sind, wenn man die Wahrschein. lichkeit des berechneten Abflusses im Vergleich mit der Wahrscheinlichkeit des FrühjahrsHochwasserabflusses, nach dem man die Berechnungen führt, um $20 \mathrm{v}$. H. vergrössert. Infolgedessen ist der Abfluss der Frühjahrs-Saatzeit nach der folgenden Formel zu berechnen:

$$
k_{\mathrm{Saatz} P+20 \%}=k_{\mathrm{Fr} \max P \%}\left(1-\frac{z P^{0,21}}{132} \sqrt[3]{k_{\mathrm{Fr} \cdot \max P \%}}\right)^{3,7}+k_{\mathrm{gr}},
$$

wo $k_{\text {Saatz } P+20 \% 0}-$ Abfluss der Frühjahrssaatzeit mit einer Wahrscheinlichkeit von $P+20$ v. H., in Einheiten des langjährigen Jahresmittelabflusses;

$k_{\text {Fr.max } P \%}-$ Frühjahrs-Hochwasserabfluss mit einer Wahrscheinlichkeit von $P$ v. H., in Einheiten des langjährigen Jahresmittelabflusses;

$z$ - Zeitabschnitt von der Spitze des Frühjahrs-Hochwasserabilusses bis zur Saatzeit in Tagen; wird nach Formel (8) berechnet;

$\boldsymbol{k}_{\mathrm{gr}}-$ Grundwasserabfluss am Ende des Frühjahrs-Hochwasserabflusses, in Einheiten des langjährigen Jahresabflusses. Beim Fehlen der Beobachtungsangaben ist als $k_{\mathrm{gr}}$ der 2,5 fache mittlere Tagesabfluss mit einer Wahrscheinlichkeit von $95 \mathrm{v} . \mathrm{H}$. $\left(k_{95 \%}\right)$ zu nehmen $\left(k_{\mathrm{gr}}=2,5 k_{95 \%}\right)$. 